\title{
Knowledge sharing about deep-sea ecosystems to inform conservation and research decisions
}

\author{
Stephanie R. Januchowski-Hartley ${ }^{a \star}$, Kimberly A. Selkoe ${ }^{\text {bcd }}$, Natalya D. Gallo ${ }^{\mathrm{e}}$, \\ Christopher E. Bird ${ }^{\text {bf }}$, and J. Derek Hogan ${ }^{f}$ \\ ${ }^{a}$ Laboratoire Evolution et Diversité Biologique, UMR 5174, UPS-CNRS-IRD-ENFA, Université Paul \\ Sabatier, 31062 Toulouse Cedex 4, France; ${ }^{b}$ Hawai'i Institute of Marine Biology, University of Hawai' $i$, \\ Kāne'ohe, HI 96744, USA; 'National Center for Ecological Analysis and Synthesis, University of \\ California Santa Barbara, Santa Barbara, CA 93101, USA; ${ }^{\mathrm{d} B r e n}$ School of Environmental Science and \\ Management, University of California Santa Barbara, Santa Barbara, CA 93117, USA; ${ }^{\mathrm{C} C e n t e r}$ for Marine \\ Biodiversity and Conservation, Scripps Institution of Oceanography, University of California San Diego, \\ La Jolla, CA 92083-0202, USA; ${ }^{\mathrm{D} D e p a r t m e n t}$ of Life Sciences, Texas A\&M University-Corpus Christi, \\ Corpus Christi, TX 78412, USA \\ ^stephierenee@gmail.com
}

\section{OPEN ACCESS}

Citation: Januchowski-Hartley SR, Selkoe KA, Gallo ND, Bird CE, and Hogan JD. 2017 . Knowledge sharing about deep-sea ecosystems to inform conservation and research decisions. FACETS 2: 984-997. doi: 10.1139/ facets-2017-0037

Editor: Brett Favaro

Received: April 20, 2017

Accepted: August 31, 2017

Published: December 7, 2017

Copyright: (c) 2017 Januchowski-Hartley et al.. This work is licensed under a Creative Commons Attribution 4.0 International License (CC BY 4.0), which permits unrestricted use, distribution, and reproduction in any medium, provided the original author(s) and source are credited.

Published by: Canadian Science Publishing

\section{Abstract}

The Marianas Trench Marine National Monument (MNM) currently extends policy-based protection to deep-sea ecosystems contained within it, but managers require better understanding of the current knowledge and knowledge gaps about these ecosystems to guide decision-making. To address this need, we present a case study of the Marianas Trench MNM using in-depth interviews to determine scientists' (1) current understanding of anthropogenic drivers of change and system vulnerability in deep-sea ecosystems; and (2) perceptions of the least understood deep-sea ecosystems and processes in the Marianas Trench MNM, and which of these, if any, should be research priorities to fill knowledge gaps about these systems and the impacts from anthropogenic drivers of change. Interview respondents shared similar views on the current knowledge of deep-sea ecosystems and potential anthropogenic drivers of change in the Marianas Trench MNM. Respondents also identified trench and deep pelagic (bathyal, abyssal, and hadal zones) ecosystems as the least understood, and highlighted climate change, litter and waste, mining and fishing, and interactions between these drivers of change as critical knowledge gaps. To fill key knowledge gaps and inform conservation decisionmaking, respondents identified the need for monitoring networks and time-series data. Our approach demonstrates how in-depth interviews can be used to elicit knowledge to inform decision-making in data-limited situations.

Key words: deep-sea ecosystems, knowledge gaps, Marianas Trench, marine protected areas

\section{Introduction}

The deep sea (locations at $1000 \mathrm{~m}$ depth or below) is the largest ecosystem on Earth, containing numerous sub-habitats with unique abiotic and biotic characteristics (Glover and Smith 2003). Despite supporting a high diversity of organisms and the increasing exploitation of natural resources by humans, these systems remain some of the least well understood on Earth (Ramirez-Llodra et al. 2011). At the same time, anthropogenic drivers of change, including human-induced climate change, 
are thought to increasingly impact deep-sea ecosystems, processes, and species (Mora et al. 2013; Barbier et al. 2014; Levin and Le Bris 2015). Warming, acidification, deoxygenation, and alterations in productivity are considered four major anthropogenic drivers of climate change for ocean ecosystems (Bopp et al. 2013).

In response to ongoing global changes, governments are beginning to embrace large $\left(>10000 \mathrm{~km}^{2}\right)$ marine protected areas (MPAs), contributing to the increase in global MPA coverage (Gruby et al. 2016). It is assumed that ecosystems protected within these large marine reserves will be better able to adapt to changes across local to global scales, and will be less impacted by anthropogenic drivers of change such as land-based runoff, pollution, and fishing pressure. Previous studies have demonstrated large, unfished, and uninhabited remote coral reef ecosystems, such as those in the Chagos Archipelago, to be more resilient to previous warming anomalies, primarily because the region is largely devoid of chronic anthropogenic pressures (Graham and McClanahan 2013). Similarly, it is anticipated that ecological benefits will accrue to ecosystems protected within large marine reserves. Broader conclusions about the value of large MPAs are premature given how recently many of the areas have been established (Gruby et al. 2016). At the same time, investigating deep-sea ecosystems that are located within large MPAs is hindered by their remoteness, technological limitations, and the high cost of many remote sensing and in situ techniques for gathering data in the deep sea (Glover and Smith 2003). These limitations make it difficult to make informed decisions about management and policies for these deep-sea systems.

The Marianas Trench Marine National Monument (MNM), a large MPA, was established in 2009 and was designated based on the area's scientific significance (US Fish \& Wildlife Service 2010). Despite being a subject of policy-based protection, scientific understanding of potential anthropogenic impacts on these systems remains limited. Despite these limitations in data and knowledge, government agencies responsible for managing the conservation of deep-sea biodiversity within the Marianas Trench MNM require information on our best current understanding of anthropogenic drivers of change impacting these deep-sea ecosystems, as well as an understanding of current limitations in knowledge and perceived research priorities to foster more effective decision-making. Through a National Oceanic and Atmospheric Administration (NOAA) project, we were tasked with identifying, and potentially quantifying, anthropogenic drivers of change impacts on deep ecosystems within the Marianas Trench MNM. Based on initial discussions with several experts working on deepsea ecosystems in the Marianas Trench MNM, we determined it was infeasible to carry out a quantitative spatial assessment of anthropogenic drivers of change impacting these systems (sensu Halpern et al. 2008). Specifically, both data on the spatial distribution of drivers of change and knowledge of the relative ecological impact of different drivers were too limited. Given these limitations in knowledge and understanding, we used the Marianas Trench MNM as a case study (Eisenhardt 1989; Cavaye 1996) to discover more about scientists' perceptions of knowledge about deep-sea ecosystems in the study area.

The objectives of our study were twofold. First, to bring together and document scientists' current understanding of anthropogenic drivers of change and system vulnerabilities in the deep-sea ecosystems of the Marianas Trench MNM; and second, to identify the least understood deep-sea ecosystems, processes, or species in the Marianas Trench MNM, and which of these should be research priorities to fill knowledge gaps about these systems and impacts from anthropogenic drivers of change. To achieve these objectives, we conducted structured interviews with scientists that have experience and knowledge of deep-sea systems within the Marianas Trench MNM. It is important to highlight that case studies like ours are often not generalizable according to quantitative standards because qualitative research is typically specific to a single or small number of ecosystems or individuals (Maxwell 1992; Flyvjerg 2016). That said, we are unaware of similar case studies, and ours could offer 
a starting point to deepen our understanding of deep-sea research and conservation needs. Individual case studies, such as the one presented here, offer in-depth analyses and high internal validity (Gerring 2007; Flyvjerg 2016), and cross-case comparisons can deepen our understanding of the phenomena of interest (Miles and Huberman 1994).

\section{Methodology}

The Marianas Trench MNM is a large MPA founded in 2009 by a United States Presidential Proclamation, affording policy-based protection to the deep-sea ecosystems, and the species they support, within the boundaries of the monument (Proclamation No. 8335, 3 C.F.R. 3 2009). The Marianas Trench MNM consists of three units: island, trench, and volcano. The trench and volcano units are the focus of our study, but we refer to all three of these in our explanation of the study area. From 21 December 2016, the islands unit and all submerged lands associated with that unit of the Marianas Trench MNM were transferred, via patent, from the United States to the Commonwealth of the Northern Mariana Islands. This transfer means that the lands, waters, and natural resources within the islands units of the Marianas Trench MNM will be managed and maintained by the Commonwealth of the Northern Mariana Islands not the United States. The trench and volcano units, the primary focus of our study, are managed and maintained by the NOAA and the United States Fish and Wildlife Service (USFWS).

Decision makers within the responsible United States' federal government agencies (the USFWS and the NOAA) have indicated that there is a limited understanding of the anthropogenic drivers of change (e.g., climate change) in deep-sea ecosystems within the Marianas Trench MNM (S. Brooke, personal communication, 2014). Our case study was bounded geographically by the extent of the Marianas Trench MNM and seven of its deep-sea ecosystems, including the following: bathyal plain (seafloor from 1000 to $4000 \mathrm{~m}$ ), bathypelagic (pelagic zone from 1000 to $4000 \mathrm{~m}$ ), abyssal plain (seafloor from 4000 to $6000 \mathrm{~m}$ ), abyssopelagic (pelagic zone from 4000 to $6000 \mathrm{~m}$ ), hydrothermal vent (depth varies; form along mid-ocean ridges), seamount (depth varies; mountain rising from the ocean seafloor that does not reach the surface, and trench (6000-11 $000 \mathrm{~m}$; hadal zone).

We used a purposive sampling approach, recruiting both individual academic and government scientists with expertise of deep-sea ecosystems (1000 m depth or below) in the Marianas Trench MNM. We identified individuals through an initial review of the literature and an online search for deepsea ecosystems, ecology, and global change. We further recruited individuals based on suggestions from interview participants through a snowball approach. We considered the scientists we interviewed to be experts, because they had specialized knowledge about: (a) deep-sea ecosystems occurring at $1000 \mathrm{~m}$ depth or below in the Marianas Trench MNM, (b) anthropogenic drivers of change and potential impacts to the deep-sea ecosystems (at $1000 \mathrm{~m}$ depth or below) in the Marianas Trench MNM, or (c) expertise of similar deep-sea ecosystems elsewhere in the world (as determined from academic publications, involvement in global and regional scale deep-sea research projects and workshops). Based on these criteria, we identified and invited 22 deep-sea scientists to participate in this study, and of these, seven agreed to participate (32\% participation rate based on the 22 scientists initially contacted), two declined to participate, and 13 did not respond to our invitations. The names, affiliations, and expertise of the seven scientists that we interviewed are presented in Table 1; all seven respondents agreed to be identified in publications derived from our interviews.

Our interview protocol was developed over a six-month period, and rigorously reviewed by both marine scientists and social scientists, including a pilot interview with one deep-sea scientist. The protocol was also reviewed by the Texas A\&M University-Corpus Christi Institutional Review Board, and the right to conduct research involving human subjects was granted on 24 February 2015 (IRB \#139-14). All interviews were conducted by the first author, following a structured protocol, 
Table 1. Experts whose perceptions are reported in this paper $(n=7){ }^{a}$

\begin{tabular}{lcc} 
Name & Affiliation & Expertise \\
\hline $\begin{array}{l}\text { Douglas Bartlett } \\
\text { Robert Carney }\end{array}$ & University of California San Diego, USA & Marine microbial genetics \\
Jeffrey Drazen & Louisiana State University, USA & Deep-sea biodiversity \\
Lisa Levin & University of Hawaii at Manoa, USA & Deep-sea fish ecology \\
Ashley Rowden & University of California San Diego, USA & Integrative oceanography \\
& National Institute of Water \& Atmospheric & Marine benthic ecology \\
Henry Ruhl & Research, New Zealand & \\
Paul Yancey & National Oceanography Centre, United Kingdom & Deep-sea ecology \\
\hline
\end{tabular}

Note: All respondents listed here agreed to be identified in publications derived from the study interviews.

${ }^{a}$ Table is organized alphabetically by surname.

and were carried-out online using Zoom Webinar Software (Zoom Video Communications 2015) during the months of April and May 2015. Each interview lasted between 45 and $60 \mathrm{~min}$. To examine respondents' perceptions of current anthropogenic drivers of change to deep-sea ecosystems in the Marianas Trench MNM, we asked them an open-ended question:

- Currently, what are possible anthropogenic drivers of change to deep-sea systems in the Marianas Trench MNM?

To explore respondents' understanding of human-induced climate change as a driver of change in deep-sea ecosystems, we asked them additional open-ended questions, and asked them about their understanding of how climate change interacts with other drivers of change (i.e., those they identified in response to our first question) to potentially impact deep-sea ecosystems. These questions were informed by previous research on climate change and deep-sea ecosystems (e.g., Ruhl et al. 2008; Levin and Le Bris 2015).

- In what ways is human-induced climate change currently driving change in deep-sea systems in the Marianas Trench MNM?

- In what ways do the anthropogenic drivers of change you listed for Question 1 currently interact with human-induced climate change to impact deep-sea systems in the Marianas Trench MNM?

- What do you perceive to be the causes of vulnerability to human-induced climate change for deep-sea ecosystems in the Marianas Trench MNM both now and over the next several decades (to 2050)?

Finally, we asked respondents about potential knowledge gaps, including the identification of systems, species, or processes that were the least understood, and asked them to identify any perceived research and conservation management priorities for deep-sea ecosystems in the Marianas Trench MNM.

- In your opinion, which deep-sea systems, species, or processes in the Marianas Trench MNM are least understood?

- In your opinion should these systems, species, or processes be research priorities?

- If so, why, and what types of studies are needed? 
- What, if any, are critical knowledge gaps in understanding the impact(s) of anthropogenic drivers of change for deep-sea systems in the Marianas Trench MNM? What is needed to fill these knowledge gaps?

- What, if any, are critical knowledge gaps in understanding the impact(s) of anthropogenic drivers of change on deep-sea systems in the Marianas Trench MNM? What is needed to fill these knowledge gaps?

- How would you rate the current understanding of anthropogenic drivers of change to the following deep-sea systems in the Marianas Trench MNM?

Due to each individual's particular expertise and variable time constraints, the degree to which specific topics were discussed varied across respondents. Information on scientist's experience working with deep-sea ecosystems was also collected at the end of each interview. All interviews were audiorecorded and transcribed by transcription professionals at TranscribeMe (transcribeme.com/). All transcriptions were visually checked, cross-checked with notes, and then transferred and coded in Microsoft Excel by the first author. When possible, and for key topics, we indicate commonality in the expert responses. We report all expert views anonymously; interviewees were assigned a number at random, and these numbers (in parentheses) are used at beginning of excerpted quotes, indicating the response of particular respondents.

\section{Results and discussion}

We report on the views of scientists about deep-sea ecosystems in the Marianas Trench MNM, presenting perspectives on: (1) anthropogenic drivers of change; (2) human-induced climate change as a driver of change; and (3) gaps in knowledge and understanding, and perceptions about what is needed to fill the gaps.

\section{Scientists' perceptions of current anthropogenic drivers of change to deep-sea ecosystems}

When asked about potential drivers of change in seven deep-sea ecosystems (bathyal plain, bathypelagic, abyssal plain, abyssopelagic, hydrothermal vent, seamount, or trench), the majority of respondents could not comment on drivers of change specific to a system or depth zone. Instead, respondents tended to identify both observed and possible anthropogenic drivers of changes to all ecosystems occurring below $1000 \mathrm{~m}$ in the Marianas Trench MNM. Where possible, we highlight drivers of change to specific systems as provided by respondents.

One respondent also stated that they were unable to comment on drivers of change in the Marianas Trench MNM, specifically, and did not offer a response. All other respondents offered responses based on their knowledge of deep-sea ecosystems in the Marianas Trench MNM or in other regions, and drew on broader knowledge and understanding of anthropogenic drivers of change to make informed statements about possible anthropogenic drivers of change to the deep-sea ecosystems in the Marianas Trench MNM. Where applicable, we include an indication of certainty in responses about an anthropogenic driver of change, for example:

(4) The ocean is warming. It's maybe not as warm at the Mariana [Trench] as some other places, but it is warming. That potentially is going to affect a lot of different things. We don't know exactly how, but it probably require [s] more energy.

In such cases, where respondents seemed to draw on experience or knowledge from other regions we asked them to clarify if they were referring to the Marianas Trench MNM specifically or if they were drawing on knowledge and understanding from other regions and ecosystems. These clarification 
questions helped us to better interpret the extent of knowledge and understanding of the ecosystems and drivers of change in the Marianas Trench MNM specifically.

Respondent opinion varied, but the majority (five of the six respondents) broadly perceived that fishing, climate change (primarily through changes in ocean acidification), and the dumping of physical, non-biodegradable waste (e.g., plastics, ammunition, mining waste) are current anthropogenic drivers of change influencing deep-sea ecosystems in the Marianas Trench MNM:

(3) ... on the sea mounts, there is the potential for fishing. Whether that extends below a thousand meters, we don't know, because I'm not convinced that we have a very good idea of what the seamount fish resources are like in some of the seamounts in this area.

(2) I don't have any insight into what we can expect in the deeper ocean ecosystems from ocean acidification. But that's certainly going to have some influence as well. Other influences within the [Marianas Trench] Marine National Monument, it's just going to be the garbage-the refuse-that we release from the surface that settles down.

(5) We know that material is sinking down there. In other abyssal systems, I've been analysing fish and I find that they have higher mercury levels than shallow fish, and we're about to do that on some Mariana trench fish.

(2) ... in the Challenger Deep [hadal trenches], in 2012, I was really struck by the fact that there was this-well, it looked like a small metallic box on the floor within the Challenger Deep and I'm not exactly sure where that comes from. But, I've got some guesses anyways. It's obviously man-made. So, even in the Challenger Deep, there's been some man-made items that are visible or at least were visible.

Other views were less commonly volunteered, and often were not attributed to a single system, per se, but perceived to impact "bottom" ecosystems such as bathyal and abyssal plains as well as trench ecosystems. One respondent identified that pollution, in the form of noise, light, chemical, and biodegradable waste (e.g., plant, animal byproducts), is likely to be an anthropogenic driver of change for plains and trench ecosystems. Recently, and after the completion of our interviews, Jamieson et al. (2017) showed that persistent organic pollutants are present in trench ecosystems in the Marianas Trench MNM, and that polychlorinated biphenyl concentrations were exceptionally high in amphipod species. Our respondents' perceptions about anthropogenic drivers of change in the Marianas Trench MNM corroborated with earlier findings (Halpern et al. 2007) about scientists' perceptions of anthropogenic drivers of change influencing the world's deep-sea environments.

It is worth reiterating the difficulty that the respondents had with assigning anthropogenic drivers of change to specific deep-sea ecosystems. Respondents consistently highlighted limited understanding of human impact on specific deep-sea ecosystems, and tended to associate gaps in knowledge for the Marianas Trench MNM with limited research and sampling opportunities.

\section{Human-induced climate change and deep-sea ecosystems}

We were also interested in scientists' understanding of how human-induced climate change is a driver of change in deep-sea ecosystems, and their understanding of how climate change interacts with other drivers of change (those presented above) to impact deep-sea ecosystems. Nearly all respondents (five of the seven) identified climate change as an anthropogenic driver of change to deep-sea ecosystems, but found it challenging to explicitly identify the ways that it is driving change in deep-sea ecosystems in the Marianas Trench MNM. Two respondents could not respond or thought that our current 
understanding was too limited to comment specifically about how climate change is driving change in deep-sea ecosystems of the Marianas Trench MNM, specifically.

(3) We have no idea; that's the short answer. I can tell you about how climate change may be affecting things either off the coast of California, or on the Porcupine Abyssal Plain, or on some of the continental slopes elsewhere in the world. But we have no such studies in the deep areas of the Marianas Trench Monument.

Drawing on knowledge from deep-sea ecosystems in the Marianas Trench MNM as well as other deep-sea ecosystems, the majority of respondents perceived that climate change is influencing changes in productivity (i.e., food supply) and increasing acidification and water temperatures in the Marianas Trench MNM.

(1) The [change in] net primary productivity is going to affect all the depths. It attenuates, but the deeper depths tend to be lower food, although trench ecosystems are much higher food ecosystems anyway. So I don't know if they'll be as sensitive to the changes. It's hard to say.

In addition to identifying individual anthropogenic drivers of change and potential impacts on deep-sea ecosystems, a growing number of studies focus on the cumulative impacts of anthropogenic drivers of change on different ecosystems (Halpern et al. 2008). We asked our group of deep-sea scientists about the potential interactions between the different anthropogenic drivers of change that they perceived to be impacting deep-sea ecosystems in the Marianas Trench MNM. We also asked the scientists to identify the causes of deep-sea vulnerability to human-induced climate change. The majority of respondents indicated that based on current knowledge it was difficult to identify how human-induced climate change could interact with other anthropogenic drivers of change to impact deep-sea ecosystems in the Marianas Trench MNM.

(2) One could speculate that by having a significant input into energy sources for organisms in hadal ecosystems, you're going to influence the kinds of micro-organisms that flourish there and that's going to have a variety of follow-on effects. But we don't know that that's the case at all, so that's pure speculation.

More than half (four of the seven) of the respondents couldn't comment on the causes of deep-sea ecosystem vulnerability to human-induced climate change in the Marianas Trench MNM. The remaining respondents highlighted that deep-sea ecosystems, apart from hydrothermal vents, both in the Marianas Trench MNM and more broadly, are vulnerable to human-induced climate change because the ecosystems are typically food limited, the species are slow-growing and longlived (some fishes are decades and even centuries old), and the surrounding ecosystem (temperature, water $\mathrm{pH}$ ) has been relatively constant for millennia (Glud et al. 2013; Mora et al. 2013).

(3) They're vulnerable because they are typically food-limited ecosystems, and the processesthe ecological processes-proceed at very, very slow rates in the deep sea.

(5) For the deep sea, what we don't know is how adaptable those organisms are. I suspect they're less adaptable because they've been in very constant ecosystem as far as temperature goes, for example. You get below 1000 meters and it's pretty much the same temperature for millennia, maybe around two degrees centigrade.

Respondents highlighted the dependence of deep-sea ecosystems on food supplies from shallow water ecosystems, a point also raised by Glud et al. (2013). It was noted that as shallower water ecosystems are impacted by climate change or other anthropogenic drivers of change, food supplies to the deep 
sea could change. Given the low-energy state of deep-sea ecosystems, any changes to available food supply from above could further increase vulnerability (Ruhl et al. 2008).

(5) So even if there isn't a direct effect on the deep sea, which there probably is, but even without that, if we decrease the amount of plankton and so on in the shallow sunlit waters, that's going to greatly reduce the amount of food in the deep sea. So it's [being] only dependent on that one food source that could make them more vulnerable as well.

Overall, respondents shared that a general lack of knowledge exists about anthropogenic drivers of change, particularly with regard to climate change, in the Marianas Trench MNM, and consistently linked this to limitations in data and research opportunities. Perhaps not surprising, then, respondents were better able to respond, and expand on their responses, to our questions about knowledge gaps and information needs.

\section{Knowledge gaps and research priorities for deep-sea ecosystems in the Marianas Trench MNM}

When considering which deep-sea ecosystems, species, or processes in the Marianas Trench MNM are least understood, respondents tended to identify particular ecosystems and processes, rather than specific species. The majority (five of the seven) of respondents highlighted that trench and deep pelagic (bathyal, abyssal, and hadal zones) ecosystems are the least understood, and suggested that these ecosystems are research priorities for this reason. Respondents stated that the trench and deep pelagic ecosystems are least understood because of the challenges of access and sampling them.

(3) You get below a thousand meters, we have no idea what lives in the water column there, let alone what kind of processes are occurring in the valley in the bathyal and abyssal pelagic. I would argue that one of the other very poorly studied habitats in this region are the bathypelagic and the abyssal pelagic.

(4) Not even scientific subs, at the moment maxing out at about six and a half thousand meters. So they're only just tickling into the trench at those sorts of depths. Trench systems basically have not been sampled very often and they have not been studied very often, and therefore we know the least about them.

In addition to identifying those systems that are least understood, respondents highlighted gaps in the knowledge of ecosystem processes, and further identified these as research priorities. Respondents noted a lack of basic understanding of trench and deep-sea pelagic ecosystems, the species they support, and their functions; a perspective supported by Jamieson et al. (2010) in their exploration of hadal trenches. They also highlighted that within and cross-ecosystem processes are poorly understood for deep-sea ecosystems both within the Marianas Trench MNM and more broadly across the world's oceans.

(1) I think we know very little about the dynamics of these systems. ... Most of the studies are one-time studies-snapshots in time ... Connectivity-knowing how the trench populations are linked to others in other parts of the Pacific Ocean-that's an important knowledge gap.

(3) We need to understand the role of these trenches ... it looks like they're acting like faults, and they are accumulating organic matter, and that will affect the distribution of communities.

When considering critical knowledge gaps to understanding the impacts of anthropogenic drivers of change on deep-sea ecosystems in the Marianas Trench MNM, respondents further identified the need to better understand species distributions and factors that drive species distributions in all 
deep-sea ecosystems. They also identified a need for time-series data to understand variability and change because of different anthropogenic drivers of change.

(6) So basically some additional sampling, and it could be focused on a subgroup-things that might be easier to sample-and could then be extrapolated?

(7) And given that you don't understand what causes the normal distributions that puts you at great risk of being wrong when you make a management decision about what parameters are going to be impacted by human activity.

(3) For understanding the climate change effect, the acidification, and changes in food supply, we need-particularly for changes in food supply, understanding the impact of that on the deep-sea fauna requires us to understand that relationship between change and influx in community dynamics.

More specific needs were also identified, with several respondents highlighting certain anthropogenic drivers of change as critical knowledge gaps including climate change, litter and waste, and mining and fishing, as well as the interactions between these drivers of change. Indeed, scientists consistently suggested the need for broader scale, cross-ecosystem, and temporal studies to improve our current understanding of deep-sea ecosystems and the potential consequences of anthropogenic drivers of change on ecosystems, processes, and species in the Marianas Trench MNM.

(4) We understand now that plastics are very pervasive in the deep sea, and that they are being incorporated into sediments and organisms and suchlike. But I think we're a long way from really understanding what those responses are by organisms and how persistent those impacts are likely to be in the long term. I think research on litter, particularly the effect of plastics, needs to be increased.

(1) Most of the studies are one-time studies-snapshots in time. Setting up time-series studies where we can understand natural variability or changes over time and what's normal, or what's induced by humans, would be important.

In addition to our open-ended questions, we asked scientists to rank the current understanding of anthropogenic drivers of change to deep-sea ecosystems in the Marianas Trench MNM. On average, scientists ranked deep-sea pelagic and trench ecosystems as least understood (Table 2); this corroborated scientists' responses to our open-ended questions about knowledge gaps and research priorities for deep-sea ecosystems and understanding the impacts of anthropogenic drivers of change in the Marianas Trench MNM. Finally, before completing each interview we asked respondents if they had any additional information to share about the Marianas Trench MNM deep-sea ecosystems. No respondents added any new information, but several revisited earlier questions, and offered clarification where points remained unclear.

\section{Knowledge sharing and implications for research and conservation}

Deep-sea scientists highlighted broad data and knowledge gaps that limited their ability to comment on current anthropogenic drivers of change to deep-sea ecosystems in the Marianas Trench MNM. Although scientists could comment broadly on likely anthropogenic drivers of change, they often perceived that they couldn't answer in detail or with confidence about the specific anthropogenic drivers of change or their impacts on specific deep-sea ecosystems in the Marianas Trench MNM. Documenting these limitations in knowledge is essential for identifying and guiding research priorities, and in the case of the Marianas Trench MNM is useful for highlighting the limited information to guide any possible management or policy prescription for the monument. We expand on these two points below. 
Table 2. Scientists' $(n=7)$ rankings of the current understanding of the anthropogenic drivers of change to the following deep-sea systems in the Marianas Trench Marine National Monument based rankings from 1 to 4, where $1=$ very limited understanding and $4=$ very strong understanding.

\begin{tabular}{lccccccc} 
Respondent & $\begin{array}{c}\text { Bathyal } \\
\text { plains }\end{array}$ & Bathypelagic & $\begin{array}{c}\text { Abyssal } \\
\text { plains }\end{array}$ & Abyssopelagic & $\begin{array}{c}\text { Hydrothermal } \\
\text { vents }\end{array}$ & Seamounts & Trenches \\
\hline 01 & 1 & 1 & 1 & 1 & 1 & 1 & 1 \\
02 & 1 & 1 & 1 & 1 & 1 & 1 & 1 \\
03 & 2 & 1 & 2 & 1 & 3 & 2 & 1 \\
04 & 3 & 3 & 2 & 2 & 2 & 3 & 1 \\
05 & 1 & 1 & 1 & 1 & 1 & 1 & 1 \\
06 & 1 & 1 & 1 & 1 & 1 & 1 & 1 \\
07 & 2 & 1 & 2 & 1 & 3 & 2 & 1 \\
\hline Mean & 2 & 1 & 1 & 1 & 2 & 2 & 1 \\
Mode & 1 & 1 & 1 & 1 & 1 & 1 & 1 \\
Median & 1 & 1 & 1 & 1 & 1 & 1 & 1 \\
\hline
\end{tabular}

Note: Respondent order does not correspond to the respondent sequence in Table 1 .

Our results highlight that although deep-sea ecosystems can be broadly defined by depth and topology, in the Marianas Trench MNM there remains limited understanding of the composition of ecosystems in the protected area, the processes both within and between systems, and the natural fluxes in those processes. Although we had intended to identify specific anthropogenic drivers of change impacting certain deep-sea ecosystem types, scientists consistently informed us that level of understanding did not exist for the Marianas Trench MNM. Scientists that we interviewed also consistently highlighted the need for basic understanding of many of the deep-sea ecosystems both within and adjoining the Marianas Trench MNM; a similar point to that raised by Glover and Smith (2003) for other deep-sea ecosystems over a decade ago. It is possible that respondents did not share some of their perceptions because of their uncertainty in the knowledge and understanding of a concept, ecosystem, or anthropogenic driver of change. With this in mind, one direction to expand our work could be to explore more deeply how respondents make their judgements about topics and the degree of certainty for their responses. This refinement might be most valuable if the focus of the interview is limited to a subsection or subset of questions in our interview schedule.

Based on the descriptions and perceptions shared by deep-sea scientists, knowledge and data gaps appear abundant for the deep-sea ecosystems of the Marianas Trench MNM. Through the establishment of the MNM there is now an opportunity to overcome these gaps. A dedicated team of government decision makers and related funding supports an opportunity to expand research and potential conservation efforts. Therefore, the knowledge shared and research priorities identified by scientists interviewed in our study offer a starting point to inform government and researchers about potential research priorities, and to inform conservation decisions and policies for the monument. However, it is important to highlight that although scientists can play a key role in the description of anthropogenic drivers of change and in driving the direction of research and conservation priorities, management and policy prescription for the monument will need to accommodate a broader range of stakeholders and their philosophical positions (Gruby et al. 2016). Gruby et al. (2016) highlighted, among other things, the need to identify who the different 
large MPA stakeholders are, how these individuals and groups are being identified, included, or excluded from decision-making processes, and what the potential implications of this could be for management. Indeed, a number of large MPAs, including the Marianas Trench MNM are developed through top-down processes that neglect or delay stakeholder engagement, and this has implications for stakeholders as well as ongoing management and policy prescription for the MPA.

With regard to the management and policies developed to conserve the Marianas Trench MNM, our findings suggest that data and knowledge gaps could hinder any explicit conservation actions related to anthropogenic drivers of change. The scientists that we interviewed highlighted the need for monitoring networks and time-series data to overcome these limitations in data and knowledge in the Marianas Trench MNM. The value of such monitoring networks, particularly with the ability to sample biological components, was previously highlighted by Danovaro et al. (2014) as the future for monitoring needed to evaluate the impact of climate change on deepsea ecosystems. Given the large spatial area and depths covered by the deep-sea ecosystems of the Marianas Trench MNM, achievement of such a network is likely to be challenging. However, with advancing technology this is likely to become increasingly possible over the next decade, and the Mariana Islands have been proposed as a prime location for a deep-sea marine biodiversity observation network site for the tropical Pacific (Duffy et al. 2013). Priority ecosystems identified by scientists in our study could be the focus of government funding to support the advancement of sampling strategies needed to better understand poorly studied systems in the Marianas Trench MNM.

\section{Conclusion}

The findings presented here serve to inform the research community about scientists' perceptions of the current understanding, knowledge gaps, and research needs to both better our basic understanding of deep-sea ecosystems and to guide decision-making for the Marianas Trench MNM. Given a growing number of international groups addressing questions about anthropogenic disturbance in deep-sea ecosystems (e.g., Deep-Sea Stewardship Initiative, and Deep Ocean Observing Strategy), our interviews offer informative perspectives for this emerging field of deepsea science. Importantly, the focused nature of qualitative studies like the one we have presented here often results in a smaller number of participants than quantitative studies, and because of this the exhaustive nature of each case becomes more important than the number of participants (Polkinghorne 1995). The purposive selection of participants in our study means that our sample is not necessarily representative of knowledge or perspectives held by all stakeholders with an interest in deep-sea ecosystems of the Marianas Trench MNM. However, we are confident that we have determined and qualified perspectives that currently exist about deep-sea ecosystems at or below $1000 \mathrm{~m}$ in the Marianas Trench MNM, reaching a saturation of concepts offered in scientists' responses. Although there are no published guidelines or tests of adequacy for estimating the sample size required to reach saturation, Guest et al. (2006) demonstrated, through an evidence-based approach, that meta-themes and the saturation of concepts occur between six and 12 interviews in purposive samples. Finally, our case study was intrinsic, and consequently, our findings are rather specific to the Marianas Trench MNM. However, our study has demonstrated how qualitative research methods can be used to elicit scientists' perceptions of knowledge about specific ecosystems and conservation-management cases. We also acknowledge that additional cases could provide further insights into the applicability of our results in other contexts, and so we presented the necessary methodological detail to allow for confirmative or comparative analyses. Collectively such case studies can enable generalization and collective knowledge about phenomena like anthropogenic drivers of change (Polkinghorne 1995). 


\section{Acknowledgements}

We would like to thank all of the scientists who participated to our interviews, and who assisted us with developing our expert list. We also thank three anonymous reviewers for their thoughtful and insightful comments that helped to improve the quality of our manuscript. We are grateful to the National Oceanic and Atmospheric Administration for funding this research (Award \#NA14NMF4520145, awarded to JDH and CEB). SRJ-H was supported by a Texas Comprehensive Research Fund grant from the Texas A\&M University-Corpus Christi Division of Research, Commercialization, and Outreach. We also thank K Moon and W Ryan for feedback on our interview questions, and an earlier version of our manuscript, respectively.

\section{Author contributions}

SRJ-H, KAS, and NDG conceived and designed the study. SRJ-H performed the experiments/collected the data. SRJ-H analyzed and interpreted the data. KAS, CEB, and JDH contributed resources. SRJ-H, KAS, NDG, CEB, and JDH drafted or revised the manuscript.

\section{Competing interests}

The authors have declared that no competing interests exist.

\section{Data accessibility statement}

All relevant data are within the paper.

\section{References}

Barbier EB, Moreno-Mateos D, Rogers AD, Aronson J, Pendleton J, Danovaro R, et al. 2014. Ecology: protect the deep sea. Nature, 505: 475-477. PMID: 24459714 DOI: 10.1038/505475a

Bopp L, Resplandy L, Orr JC, Doney SC, Dunne JP, Gehlen M, et al. 2013. Multiple stressors of ocean ecosystems in the 21st century: projections with CMIP5 models. Biogeosciences, 10: 6225-6245. DOI: $10.5194 /$ bg-10-6225-2013

Cavaye ALM. 1996. Case study research: a multi-faceted research approach for IS. Information Systems Journal, 6: 227-242. DOI: 10.1111/j.1365-2575.1996.tb00015.x

Danovaro R, Snelgrove PVR, and Tyler P. 2014. Challenging the paradigms of deep-sea ecology. Trends in Ecology \& Evolution, 29: 465-475. PMID: 25001598 DOI: 10.1016/j.tree.2014.06.002

Duffy JE, Amaral-Zettler LA, Fautin DG, Paulay G, Rynearson TA, Sosik HM, et al. 2013. Envisioning a marine biodiversity observation network. BioScience, 63: 350-361. DOI: 10.1525/bio.2013.63.5.8

Eisenhardt KM. 1989. Building theories from case study research. The Academy of Management Review, 14: 532-550.

Flyvjerg B. 2016. Five misunderstandings about case-study research. Qualitative Inquiry, 12: 219-245. DOI: $10.1177 / 1077800405284363$

Gerring J. 2007. Case study research. Cambridge University Press, Cambridge, UK.

Glover AG, and Smith SR. 2003. The deep-sea floor ecosystem: current status and prospects of anthropogenic change by the year 2025. Environmental Conservation, 30: 219-241. DOI: 10.1017/ S0376892903000225 
Glud RN, Wenzhöfer F, Middelboe M, Oguri K, Turnewitsch R, Canfield DE, et al. 2013. High rates of microbial carbon turnover in sediments in the deepest oceanic trench on Earth. Nature Geoscience, 6: 284-288. DOI: 10.1038/ngeo1773

Graham NAJ, and McClanahan T. 2013. The last call for marine wilderness? BioScience, 63: 397-402. DOI: $10.1525 /$ bio.2013.63.5.13

Gruby RL, Gray NJ, Campbell LM, and Acton L. 2016. Toward a social science research agenda for large marine protected areas. Conservation Letters, 9: 153-163. DOI: 10.1111/conl. 12194

Guest G, Bunce A, and Johnson L. 2006. How many interviews are enough? An experiment with data saturation and variability. Field Methods, 18: 59-82. DOI: 10.1177/1525822X05279903

Halpern BS, Selkoe KA, Micheli F, and Kappel CV. 2007. Evaluating and ranking the vulnerability of global marine ecosystems to anthropogenic threats. Conservation Biology, 21: 1301-1315. PMID: 17883495 DOI: $10.1111 / j .1523-1739.2007 .00752 . x$

Halpern BS, Walbridge S, Selkoe KA, Kappel CV, Micheli F, D’Agrosa C, et al. 2008. A global map of human impact on marine ecosystems. Science, 319: 948-952. PMID: 18276889 DOI: 10.1126/ science. 1149345

Jamieson AJ, Fuji T, Mayor DJ, Solan M, and Priede IG. 2010. Hadal trenches: the ecology of the deepest places on Earth. Trends in Ecology \& Evolution, 25: 190-197. PMID: 19846236 DOI: 10.1016/j. tree.2009.09.009

Jamieson AJ, Malkocs T, Piertney SB, Fujii T, and Zhang Z. 2017. Bioaccumulation of persistent organic pollutants in the deepest ocean fauna. Nature Ecology \& Evolution, 1: 51. PMID: 28812719 DOI: $10.1038 /$ s41559-016-0051

Levin LA, and Le Bris N. 2015. The deep ocean under climate change. Science, 350: 766-768. PMID: 26564845 DOI: 10.1126/science.aad0126

Maxwell J. 1992. Understanding and validity in qualitative research. Harvard Educational Review, 62: 279-301. DOI: 10.17763/haer.62.3.8323320856251826

Miles MB, and Huberman AM. 1994. An expanded sourcebook: qualitative data analysis. SAGE Publications, Thousand Oaks, California.

Mora C, Wei C-L, Rollo A, Amaro T, Baco AR, Billett D, et al. 2013. Biotic and human vulnerability to projected changes in ocean biogeochemistry over the 21st century. PLoS Biology, 11: e1001682. PMID: 24143135 DOI: 10.1371/journal.pbio.1001682

Polkinghorne DE. 1995. Narrative configuration in qualitative analysis. International Journal of Qualitative Studies in Education, 8: 5-23. DOI: 10.1080/0951839950080103

Proclamation No. 8335, 3 C.F.R. 3. 2009. Establishment of the Marianas Trench Marine National Monument [online]: Available from gpo.gov/fdsys/granule/CFR-2010-title3-vol1/CFR-2010-title3vol1-proc8335.

Ramirez-Llodra E, Tyler PA, Baker MC, Bergstad OA, Clark MR, Escobar E, et al. 2011. Man and the last great wilderness: human impact on the deep sea. PLoS ONE, 6: e22588. PMID: 21829635 DOI: 10.1371 /journal.pone.0022588 
Ruhl HA, Ellena JA, and Smith KL Jr. 2008. Connections between climate, food limitation, and carbon cycling in abyssal sediment communities. Proceedings of the National Academy of Sciences of the United States of America, 105: 17006-17011. PMID: 18974223 DOI: $10.1073 /$ pnas.0803898105

US Fish \& Wildlife Service. 2010. Mariana Trench Marine National Monument website. US Department of the Interior, Fish and Wildlife Service, Washington, D.C. [online]: Available from fws.gov/refuge/mariana_trench_marine_national_monument/.

Zoom Video Communications. 2015. Video conferencing and web conferencing service (zoom.us/). 